\title{
ABOUT COURTS
}

\author{
Barbara Mitchels, Roy Meadow
}

\section{Even a fool can ask a question that an expert} cannot answer

DR JOHNSON

In cases of child abuse evidence may be required from doctors in various courts. The police may prosecute the offender. The child may be the subject of care proceedings, or the child's parents may seek a court ruling on domestic issues arising from the incident.

Doctors may be called, like anybody else, as ordinary witnesses to fact - for example, when they just happened to see a road accident - but more often they are called to court as professional witnesses in relation to one of their patients, giving evidence of fact on matters arising from their professional capacity as a doctor. Sometimes a doctor not necessarily connected professionally with the case is also called in as an expert witness to give an opinion or interpret facts using specialised knowledge and experience. The distinction between a professional and an expert witness is blurred, and the courts expect all doctors to use their medical skill fully and to give an opinion based on their observations, findings, and research using reference works, notes, diagrams, and other relevant material if appropriate.

There are proposed reforms in child protection law currently before parliament in the Children Bill, which may come into effect soon, although possibly not all at once. The bill alters some things, including the grounds for child care proceedings, but, although a new family court was suggested elsewhere, the bill leaves the court system unaltered for the moment, except for a few procedural alterations. The bill provides that care cases shall be heard in the domestic section of the magistrates' court, the county court, or the High Court. There will be a system devised to decide which court will be appropriate for each case.

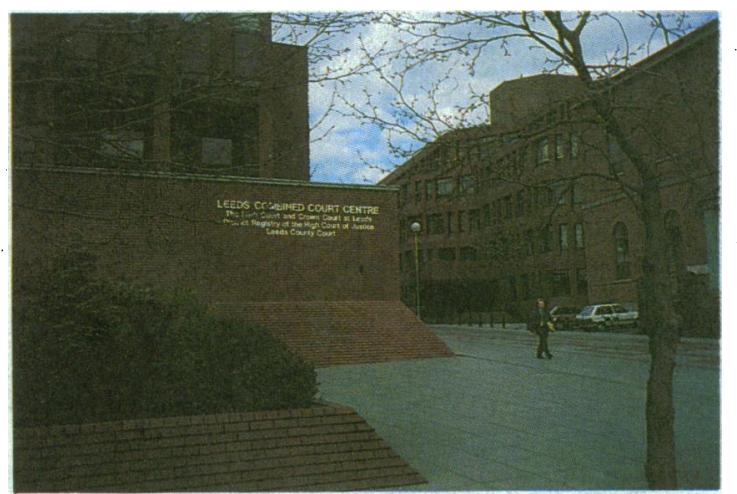

The High Court is forbidden to make care orders within wardship proceedings and limitations are set on the use of its inherent jurisdiction relating to children in other proceedings. The main body of care work will then be done in the domestic section of the magistrates' court, with some cases of greater complexity or seriousness going to the county court and the High Court.

Doctors will appear mainly in the magistrates' court or the crown court in criminal prosecutions and in the domestic section of the magistrates' court, the county court, or the High Court in care cases and civil proceedings. For those who are called to give evidence it helps to know the set up of the courts, how to address those present, and a little about the differences in procedure.

\section{Care proceedings court}

Currently most care proceedings take place in the juvenile court. The new care proceedings courts will probably be similar. The court room is informally set out. At one end sits a "bench" of three specially trained magistrates (the chairman will be the one sitting in the middle); their clerk, a legally trained adviser, sits in front of them, and in from of him or her are tables or desks for the lawyers concerned with the case, the social workers and others, the parents, and the child. Anyone not directly concerned with the case is excluded from the court. The press is allowed to be there, but reporting is restricted and the child may not be identified in any way.

Ordinary witnesses have to remain outside the court until their evidence is required. The reason for this is that they should not be influenced by the evidence of others. Expert witnesses are an exception to this rule and may sit through the case until their evidence is called and remain thereafter if they wish. It is very useful to hear the evidence of other experts, together with the general evidence, to get a clear picture of all the relevant issues. Sit near the instructing advocate (solicitor or barrister) if possible-advocates may need a helpful word of advice as they conduct their case.

As a matter of courtesy, silence is observed in court during the proceedings by all who are not actively taking part. The court will take a dim view of whispered conversations at the back, so unless a matter requires urgent discussion it is better to pass a note or go outside to converse. If something needs to be communicated to advocates try to attract their attention unobtrusively and they can, if necessary, ask the court for a short adjournment to deal with it or 
ask the court to pause for a moment while they take instructions.

There are no hard and fast rules as to whom professional or expert witnesses may speak before the case. Doctors may wish to confer with each other, and they can usually do so easily, but it is courteous to confer in the presence of their respective instructing advocates. It also shows the parties to the case who may be feeling vulnerable that they are not being "stitched up" by the experts. If speaking to a non-medical witness to ascertain some vital information is absolutely necessary it should be done through, or in the presence of, the appropriate advocates as there must be no question of possible influence being brought to bear by anyone on another's evidence.

During the case it is wise to consult your advocate about the propriety of discussions with another witness or party.

The court has to find the case proved on a balance of probabilities, and rules exist about the evidence that may be produced to satisfy the burden of proof. The most tricky to deal with is "the hearsay rule," which prevents witnesses giving evidence of any events that did not occur in their presence and also (with some exceptions) from relating to the court anything that was said by another person to them. In child care cases this rule of evidence is relaxed because the court needs to get at the truth and because sometimes a chance remark or admission may be germane, particularly in cases of abuse. When a doctor needs to quote a fact from medical records, possibly referring to an incident noted by a colleague, it would normally fall foul of the hearsay rule as the incident quoted did not occur in the witness's presence, but there are exceptions, with safeguards, to enable such evidence to be given in court.

\section{Criminal proceedings}

Criminal cases are tried in the juvenile court (if the accused is under 17), magistrates' court, or crown court.

Appeals from the magistrates' court on matters of fact are heard in the crown court by way of a retrial, and appeals from the magistrates' court on matters of law are heard in the divisional court of the Court of Appeal by way of case stated - that is, without hearing the live evidence again.

Appeals from a trial at the crown court pass usually to the Court of Appeal (criminal division) and then on a point of law of public importance to the House of Lords.

In criminal prosecutions resulting from alleged child abuse doctors will be called mainly before the magistrates' or crown court. The burden of proof in criminal trials is to satisfy the court beyond reasonable doubt that the accused is guilty of the crime alleged. As the accused's liberty and reputation are probably at stake the standard of proof is higher and the rules of evidence are therefore more strictly applied. The Police and Criminal Evidence Act 1984 governs the procedures for interviewing suspects, the taking of intimate samples from suspects, and much of the preparation and presentation of evidence in court. Unlawfully gained evidence may be excluded.

Doctors may therefore find themselves in court giving evidence about examination of either a victim or a suspect, and it is important to remember that the rules for each are different. Examination of a child for evidential purposes must currently be with the consent of a parent, or guardian, or of social services when a place of safety or care order places the child in the care of a local authority. After the Children Bill comes into force medical or psychiatric examinations may require the consent of the court. Examination of a suspect must be in accordance with the provisions of the Police and Criminal Evidence Act 1984.

In the magistrates' court the layout of the court room and the bench is similar to that described in the juvenile court but more formal. The accused will be in a dock, possibly guarded, and the court room will usually have specific areas in which advocates, public, police, and others in the cases will sit during the proceedings.

The public is allowed into court, and the press present may report the case, with safeguards, provided that the child's identity is not disclosed.

\section{Crown court}

Criminal prosecutions in the crown court follow the same rules of evidence as those outlined above for trials in magistrates' courts. The trial will, however, take one of two possible forms. If the plea is guilty the hearing will be before a judge, whose task is to hear the facts of the case outlined by the prosecution and the mitigation for the accused and to sentence the offender after considering the circumstances of the offender and of the offence, together with any reports presented to the court. If it is a contested case the judge will sit with a jury. The jury will be the arbiters of fact in the case, and the role of the judge is to advise the jury on matters of law and evidence and to sentence the offender if he or she is found guilty, again after full consideration of the circumstances and available reports.

Sentence may be delayed to obtain any further relevant reports required.

When the trial is by jury the court may seem rather theatrical to witnesses and onlookers. The images of Perry Mason or Marshall Hall may affect behaviour and attitudes unless carefully watched. It is tempting to want to impress the 12 people in the jury box with your knowledge, personality, or persuasive speeches, and their rapt attention to the evidence is very flattering. But bear in mind that they are people who are doing their best to understand the issues in the case and that they need a clear and concise explanation of the facts and opinions given. They are unlikely to be impressed for very long by meaningless waffle. The judge certainly will not be impressed at all and may well intervene if a medical witness seems to be going off the point.

The waiting rooms in crown courts are often better than those in the magistrates' courts, and there is usually a canteen to keep you going 


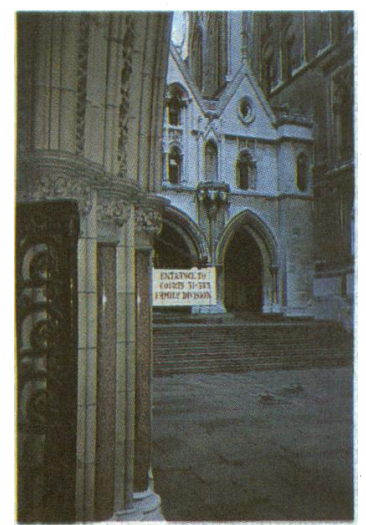

Courtyard and entrance (below) of Royal Courts of Fustice, London during the seemingly eternal wait to be called. The trials are usually longer in the crown courts, and the court may be less willing to make special allowances for expert witnesses to get away quickly, although most do their best to accommodate doctors, knowing that they have many pressing demands on their time.

Telephones are usually available for public use.

Be well prepared for trials by jury, making sure that you have sufficient copies of diagrams, documents, or reports to be used in evidence for the judge, clerk, and the jury, as well as for the advocates and the parties to the case. Medical records and clinical notes are not usually copied, for obvious reasons. Though they may be needed for the doctor's own reference, they would not usually be handed over to anyone else, unless the judge gives a specific direction.

\section{Civil cases and care proceedings in county court and High Court}

Most civil cases are tried in the county courts or the High Court, civil division. The case of the plaintiff (person bringing the action) must be proved on a balance of probabilities and the rules of evidence observed. After the Children Bill is enacted care cases will be heard not only in the domestic section of the magistrates' court but also in the county court and the High Court. It may become possible to move proceedings from one court to another, but the appropriate procedures for transfer and the way in which the venue for the start of care proceedings is to be decided are yet to be laid down in rules to be made by the Lord Chancellor.

The county courts have judges, and also registrars (rather like junior judges), who deal mainly with the preliminary pretrial issues and some non-contested cases.

Evidence in the civil courts is given either orally or by affidavit, or sometimes both ways.

If an expert is asked to prepare a report for a civil case the report will (if it is to be used in evidence) be put into the form of an affidavit by the solicitor for the party calling the witness and then be disclosed to the other side at or after the pretrial review of the case before the registrar. The evidence may then be agreed, in which case the witness need not attend the trial and the affidavit can be read; if, however, it is not agreed the witness may be called to court to give oral evidence. Oral evidence of expert witnesses may then be limited to occasions requiring elucidation or cross examination, saving the experts' and the court's time.

\section{Going to court}

Many doctors ask if they have to go to court if asked to do so. In a criminal trial if any person is in possession of facts that are material to the case to be heard before the court, and the court is persuaded that their evidence is both relevant to the issues and vital to the case, the court may order the person to attend as a witness. The court may issue a witness summons, which requires the person named in it to attend the trial. The person summoned is answerable to the court for failing to attend and a penalty may be imposed for not attending. The county court and High Court also have the power to issue a witness summons (subpoena) and order the person to produce relevant documents to the court (subpoena duces tecum). Again, as the name suggests, a penalty is forthcoming for disobeying the order.

When the evidence is opinion based on observations after an event - for example, the findings on interview of a suspect by a clinical psychologist after an alleged confession to a serious crime - the question arises whether the expert may be forced to come to court and in what circumstances. An expert could be called in by the defence in the course of preparation of a case and prepare a report that proves unfavourable to the defence case. At this stage the defence may decide not to call that witness. It may choose to have the witness in court to assist in the conduct of the case, possibly by suggesting questions in cross examination, but not to ask that expert witness to give evidence. There is no duty to disclose an unfavourable report to the prosecution. But note that section 81 of the Police and Criminal Evidence Act 1984 enables the Crown Court to require either party to disclose to the other any expert evidence to be adduced in the proceedings. Any such evidence not so disclosed may not be adduced without the leave of the court.

\section{Giving evidence}

It is usual to stand when giving evidence but you may be asked whether you wish to sit. By tradition, advocates rarely sit and as it is easier to communicate with someone who is in the same posture as you; standing at ease but not easy is probably best.

In the magistrates' court replies to questions from an advocate should be directed not to the advocate but to the bench, speaking to the chairman. When speaking to one magistrate about another, perhaps referring to a remark or question from another person on the bench call the other "your colleague." In county courts or the High Court speak to the judge.

Do not be rushed, and be prepared to use the medical records before answering a question.

Any relevant notes, diagrams, and photographs or radiographs may be referred to in giving evidence. If the notes - for example, medical records - have been made by someone else they may be used if they form part of a continuous record and were made by people who have no personal interest in the case. If photographs or radiographs are challenged the advocate may need to call the person who took them to formally produce them in evidence. Charts, reference works, and tables may be used if necessary.

Aim to be concise and clear. Speak loudly enough for everyone to hear and slowly enough for the stenographer or judge to take notes. It is better to speak too slowly than too fast. It is better to speak too loudly than too softly. 


\section{Forms of address}

- My Lord or My Lady: Lords of Appeal (sitting in the House of Lords); Lords Justices (sitting in the Court of Appeal); High Court judges or any deputy sitting as a High Court judge; and all judges sitting at the Central Criminal Court (the "Old Bailey")

- Your Honour: all circuit judges sitting in the crown court or the county court; recorders; and most other judges in the Commonwealth or United States

- Sir or Madam, or less commonly now, Your Worship: magistrates

It is customary to stand and bow to magistrates or judges when they enter or leave the court room. Similarly, when you enter or leave a court that is in session a modest bow to the bench or judge is appropriate
If you do not know the answer to a question say so briefly and succinctly: "I do not know" or "No"; it is unwise to make excuses for yourself unless you are asked for them. Being in court is rather like the viva in an examination. It pays to listen carefully to the question and to answer only the question. Put first things first and do not bring in extraneous matter or subjects about which you know little.

As a medical witness your role is to serve neither the prosecution nor the defence but the court. When the court is considering child abuse your duty is to the welfare of the child. On this basis a doctor should be above any partisan feelings and not influenced by any matter other than the welfare of the child. All questions should be answered with this in mind.

Expert witnesses have additional roles. The duty of the expert may include explaining child development, child behaviour, and the effect of adverse factors such as abuse on the child. Thus the expert is drawing attention to the particular needs of the child for the benefit of those who have less experience with children.

As with all speaking engagements, first and last impressions count. Therefore, remember that at the start everyone will be watching and listening to you and similarly at the end when you leave the witness box. Make a good exit, picking up your notes efficiently before bowing to the judge or magistrate. Expert witnesses may wish to remain to the end of the case, but if not the court will usually release them promptly. If the advocate has not asked for you to be excused from the court ask the magistrate, "May I be released? I can be reached by telephone and return if the court wishes."

In their efforts to be fair to all parties court proceedings are subject to many adjournments and delays. The court officers are, however, considerate of doctors' time and make every effort to call their evidence as soon as possible. When you are asked to attend court it is useful to have your diary available and to specify particular times or days when it is difficult to attend because of clinical commitments.

The British Medical Association produces for its members a leaflet (No 33) which provides guidance on legal fees and allowances.

\section{ANY QUESTIONS}

What is the likely cause of and treatment for recurring ischiorectal abscesses in a man in his 70s?

In any patient who has a recurring infection it is a good rule to exclude any general factor, so in this patient diabetes mellitus should be excluded by testing the urine for sugar and carrying out a blood glucose estimation. Most recurrent abscesses in this region are undoubtedly due to repeated infection of a fistula in ano. A barium enema or sigmoidoscopy would not show a fistula tract. This can be diagnosed only by a careful examination under anaesthesia. There may be an external opening, revealed on careful probing of the perianal skin. Even if this is intact an internal opening, often hidden at the base of an anal crypt, may be detected if the anal canal is carefully searched with the aid of a bivalve speculum and a malleable metal probe.
Infection may reach the ischiorectal fossa through abrasions in the perianal skin, which should be carefully scrutinised for any chronic skin lesion. Minute tears in the anal canal may also serve as portals of entry of organisms. Judicious inquiry should be made of the patient about insertions of foreign bodies into the rectum.

Rare causes of chronic ischiorectal abscess are Grohn's disease and tuberculosis. A chest $x$ ray examination should be carried out to exclude a pulmonary tuberculous lesion. Biopsy material from the abscess should be sent for histological examination and, specifically, mycobacteria should be sought. Leukaemia is another rare underlying cause which could be excluded by a leucocyte count. 